\title{
BODAS DE PLATA 1992-2017. FACULTAD DE MEDICINA UNIVERSIDAD NACIONAL SAN LUIS GONZAGA. ICA, PERÚ.
}

\section{Correspondencia}

Jorge Ybaseta Medina

Villa del Médico B-7 Ica, Perú.

956747941

jybaseta@unica.edu.pe

Recibido: 05/11/2017

Aprobado: 20/11/2017

Citar como:

Jorge Ybaseta-Medina. Bodas de Plata 1992-2017. Facultad de Medicina Universidad Nacional San Luis Gonzaga. Ica, Perú. 2017; 6(3): 125 127
Jorge Ybaseta-Medina ${ }^{1,2, a, b}$

1. Director de la Revista Médica Panacea

2. Facultad de Medicina Humana de la Universidad Nacional San Luis Gonzaga. Ica, Perú.

a. Doctor en Medicina Humana

b. Gineco-obstetra del Hospital Santa María del Socorro de Ica, Perú.

Señor Editor:

Considerando ser integrante de la Promoción 1992 no puedo dejar pasar por alto el día 28 de octubre del año 2017 donde se realizó la celebración de las bodas de plata de la Promoción Luis Tolmos Regal (LTR) de la Facultad de Medicina Daniel Alcides Carrión" de la Universidad Nacional San Luis Gonzaga de Ica, Perú.

El acto tuvo la participación de un importante número de integrantes de la Promoción que vinieron de diferentes partes del mundo, siendo el Rvdo. Padre Alfonso Berrade quien se encargó de dar inicio a la programación establecida con una excelente paraliturgia seguidamente el representante de la promoción el Dr. Juan Menéndez da la bienvenida al Decano de la Facultad de Medicina Dr. Benito Díaz López quien expresó su saludo a los miembros integrantes de la promoción y felicitó a esta promoción porque tiene historia de gloria, con ella nació la estudiantina médica, se inició la construcción de la gruta de la Virgen María Auxiliadora, se creó la Sociedad de Científica de Estudiantes de Medicina (SOCEMI), se hizo el logotipo de la facultad, se refirió también a estudiantes de la promoción que jugaron en el equipo de futbol el Estudiantes de Medicina al final dijo que era una promoción multifacética.

Sin duda es una de las mejores promociones conformada por alumnos que vinieron desde la selva, el norte, centro, sur del país y nuestro departamento, muchos estudiaban en universidades del país y 25 años después casi en su totalidad laboran como médicos especialistas, subespecialistas, muchos de ellos son funcionarios en institutos, hospitales importantes del país y el exterior, todos con éxito.

La clase magistral del recuerdo estuvo a cargo del Doctor Luis Tolmos Regal, fue emotiva iniciándose con una exposición de fotos inolvidables pertenecientes a la promoción que lleva su nombre, el tema de la clase fue predominantemente la historia de nuestra facultad( $(1,2)$, sobre la contribución del Dr. Aníbal Casavilca Rubio ex Decano de la Facultad de Medicina y muy a su estilo se refirió sobre el sacrificio, abnegación y ética del médico, recibiendo al final de su exposición muestras de admiración y afecto.

Acto seguido se realizó la renovación del Juramento Hipocrático de parte de todos los integrantes de la Promoción y la importante iniciativa de efectuar una valiosa donación consistente en dos equipos de audio y micrófonos inhalambricos para beneficio de los estudiantes.

El Auditórium se veía repleto por integrantes de la promoción como en aquellas clases del Dr. Víctor Torrealva Anchante momento en que el Decano de la Facultad de medicina invita al autor de esta carta para entregarle un diploma de 25 años de labor médica instante que da homenaje a todos y cada uno de los integrantes de la Promoción LTR, finalizando la ceremonia en el auditórium con el Himno de nuestra Facultad de Medicina, letra y música del ex alumno Armando Massé actualmente presidente de la Asociación Peruana de Autores y Compositores. 
Toda la promoción a la orden del Dr. Tolmos se organizó al frente a los monumentos de nuestros mártires de la Facultad de Medicina Victoria Astupiña Barrionuevo (3) y Víctor Raymundo Luna Benavides en uso de la palabra el Doctor hizo remembranza como dieron su tiempo, energía y su vida para que la Universidad San Luis Gonzaga tenga campo clínico para sus estudiantes de medicina en el Hospital Regional de Ica, Los mártires de nuestra facultad recibieron merecidos honores.

Considerando la brevedad de la vida y que el futuro no se puede determinar exactamente, pregunto ¿ sería posible reunirnos en las bodas de oro con mi promoción?
Sin embargo tengo la esperanza que alguien más escribirá ese momento!

Quiero culminar este informe diciendo, que con el paso de los años, presenciamos el desarrollo y el crecimiento de la facultad de medicina; este es el momento de agradecer y no olvidarse de su alma mater, ni de sus profesores. Recordar siempre que nosotros somos el camino y para salir adelante, no debemos de olvidar que la juventud es una fuerza vigorosa tal como lo dijo Claude Bernard (1).

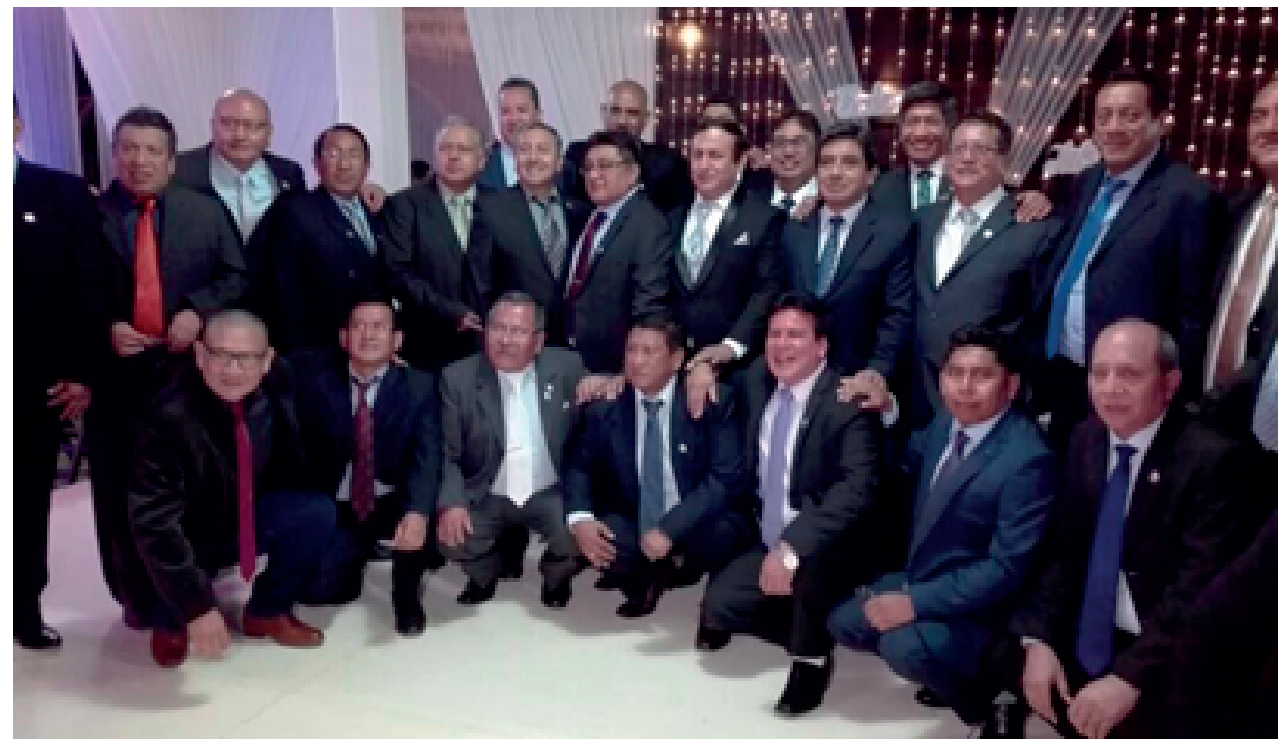

Figura 1: De pie: Jaime Gutiérrez, Marco Lujan, Ismael Gonzales, Pepe Untiveros, Edwin Noli, José Soto, Orlando Álvarez, Walter Lujan, Jorge Ybaseta, Felipe Carrillo, Andrés Yauricasa, Lucho Ormeño, Jorge Uchuya, Miguel Meza y Marcos rojas. De cuclillas: Leoncio Crisanto, Oscar Tapia, Nazario Muchotrigo, Alfonso Gallo, Carlos Ventura y Ronald Sánchez.

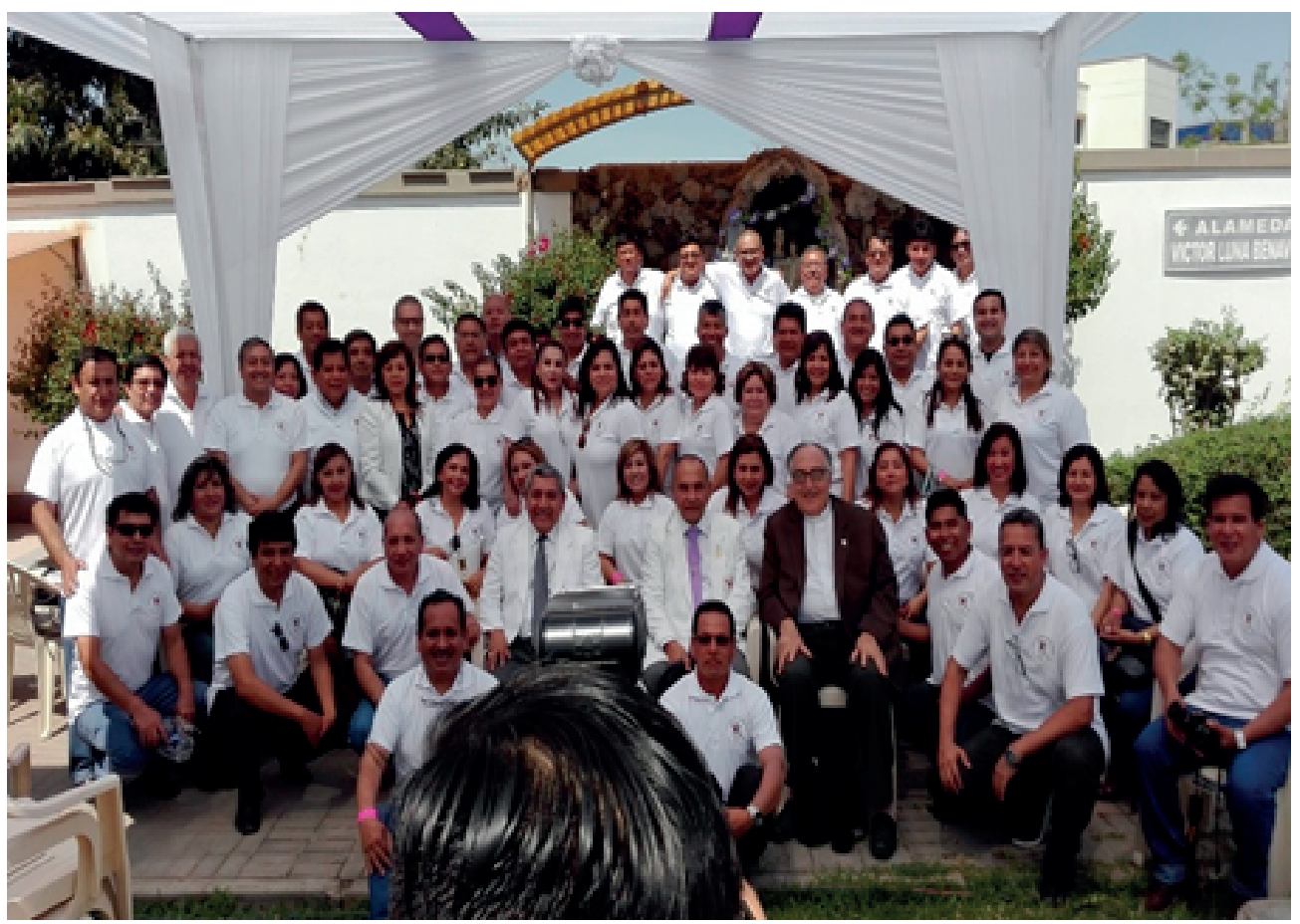

Figura 2: Promoción LTR acompañan Dr. Benito Díaz, Luis Tolmos Regal y el Rvdo. Padre Alfonso Berrade. 
REFERENCIAS BIBLIOGRÁFICAS

1. Román Ruíz C. Breve reseña histórica de la facultad de medicina de Ica. Rev méd panacea.2013; 3(3):87-88.

http://revpanacea.unica.edu.pe/index.php/RMP/arti cle/view/119/96

2. Luis Tolmos Regal. Editorial. Rev. Méd . panacea 2011; 1(1):1
http://revpanacea.unica.edu.pe/index.php/RMP/arti cle/view/14/9

3. Sebastián Legua-Pérez, Gina Munive Sivirichi, Julio Taquiri Gonzales. Victoria Astupiña Barrionuevo, Martir de la educación, a 50 años de su muerte.

http://revpanacea.unica.edu.pe/index.php/RMP/arti cle/view/49/29

\section{Las ediciones anteriores de revista médica PANACEA están disponibles en:}

\section{www.revpanacea.unica.edu.pe}

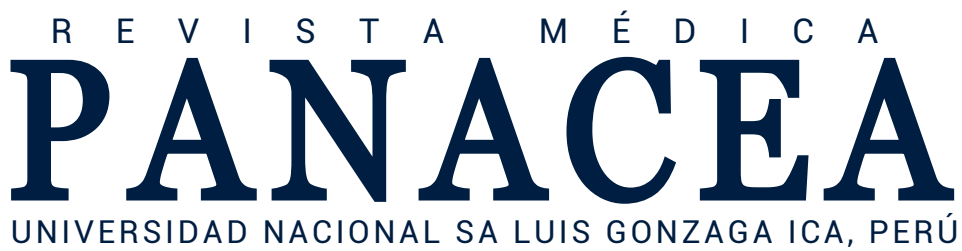

